\title{
POLÍTICAS PÚBLICAS E O MEIO AMBIENTE: O DESAFIO DA AVALIAÇÃO E MONITORAMENTO
}

\section{Luiz César Ribas ${ }^{1}$}

\section{Leonardo de Barros Pinto²}

\section{Mariane Branco Vilela Meirelles ${ }^{3}$}

RESUMO: O objetivo do desenvolvimento sustentável vem sendo buscado no Brasil desde a década de 1980, por ocasião da promulgação da Política Nacional do Meio Ambiente (Lei n. 6.938, de 31 de agosto de 1981). De lá para cá, e após a Conferência das Nações Unidas sobre o Meio Ambiente e o Desenvolvimento, também conhecida como ECO-92, Rio-92, Cúpula ou Cimeira da Terra, diversas políticas ambientais têm sido elaboradas sobre temas, desdes os mais tradicionais e clássicos (recursos florestais, recursos hídricos), até os mais recentes (resíduos sólidos, remueração de serviços ambientais). Este trabalho se propõe a apontar, descrever, sistematizar e selecionar alguns dos principais parâmetros que devem ser considerados, dentro de uma leitura predominantemente econômica, para efeitos de se avaliar e monitorar as políticas públicas na área ambiental. Como hipótese principal, defende-se que é possível indicar critérios que possam orientar a avaliação e acompanhamento das políticas públicas ambientais por parte dos distintos segmentos da sociedade e segundo diversos interesses específicos. Pretende-se utilizar o método indutivo para fins de se estabelecer uma

\footnotetext{
1 Engenheiro Florestal, Departamento de Economia, Sociologia e Tecnologia, Faculdade de Ciências Agronômicas, Universidade Estadual Paulista "Júlio de Mesquita Filho" (UNESP). Professor Assistente Doutor. E-mail: Icribas@fca.unesp.br

${ }^{2}$ Engenheiro Agrônomo, Departamento de Economia, Sociologia e Tecnologia, Faculdade de Ciências Agronômicas, Universidade Estadual Paulista "Júlio de Mesquita Filho" (UNESP). Professor Assistente Doutor. E-mail: leo@fca.unesp.br

${ }^{3}$ Bacharel em Direito. Programa de Pós-Graduação em Ciência Florestal. Universidade Estadual Paulista "Júlio de Mesquita Filho" - Campus Botucatu/SP. E-mail: mariane_meirelles@yahoo.com
} 
conclusão que confirme ou afaste a hipótese principal deste trabalho. Foram identificados, ao final, alguns dos principais parâmetros que poderiam auxiliar, os segmentos da sociedade direta ou indiretamente envolvidos em determinado tema ambiental, a discutir, avaliar e monitorar os instrumentos de comando e controle, econômicos e outros consoante propostos para a implantação de um política pública ambiental.

Palavras chave: Política Pública, Meio Ambiente, Critérios de Avaliação.

\section{INTRODUÇÃO}

Segundo Almeida (1998) e Da Motta et Mendes (1999), "política pública"4 é o resultado final de toda a elaboração de uma estratégica para a aplicação de instrumentos de ação ou seja, meios desenvolvidos pela Economia, Legislação, Administração de Empresas, Engenharias e demais áreas do saber com vistas a objetivos prédeterminados.

Destes autores depreendem-se, ainda, que determinada política pública deve ter como foco, não somente o objetivo específico para a qual uma estratégia foi formulada (proteção ambiental, por exemplo), mas também objetivos pré-determinados, quais sejam: crescimento econômico; repartição de renda; estabilidade do processo econômico; e geração de riqueza e emprego.

Na política pública relacionada à proteção ambiental, verifica-se que tão importante quanto os objetivos mencionados, uma determinada política ambiental deve se pautar, no seguinte conjunto de instrumentos de ação (meios) para a consecução dos objetivos (finalidades) de uma política pública: (i) instrumentos econômicos tais como os "monetários" (Teoria da Moeda; moeda e crédito, além de demais tipos de operações monetárias), os "cambiais" (Teoria das Relações Internacionais; manejo da taxa de câmbio) e os "fiscais" (Teoria das Finanças; subsídios fiscais e isenções tributárias, dentre outros exemplos); (ii) instrumentos de comando e controle (Teoria do Direito: leis, regulamentos, normas e demais dispositivos legais); e (iii) instrumentos coadvujantes (Análise Microeconômica; controle direto sobre as atividades das empresas, sobre os

\footnotetext{
${ }^{4}$ Política pública pode ser entendida, também, como sinônimo de "Política Econômica".
} 
preços dos recursos de produção e dos produtos finais e mesmo sobre o comportamento dos consumidores), conforme depreende-se de Almeida (1998), Da Motta et Mendes (1999), Silva et Da Cunha (2007), Marques (1999) e Mueller (1994).

Segundo ainda se estabelece destes autores, a política agrícola brasileira ${ }^{5}$ baseouse, durante muito tempo, em instrumentos fiscais e, mais recentemente, justamente por conta da "interface" com a questão ambiental, em instrumentos de comando e controle (definição de padrões ambientais, normas de implantação de empreendimentos industriais, multas, etc.), bem como em instrumentos econômicos ${ }^{6}$ (princípio do usuáriopagador, poluidor-pagador, princípio do provedor-recebedor, remuneração de serviços ambientais, dentre outros tipos).

Note-se que princípios tais como, o do provedor recebedor ${ }^{7}$, dentre outros (a prevenção e a precaução; o poluidor-pagador e o protetor-recebedor; a visão sistêmica, na gestão dos resíduos sólidos, que considere as variáveis ambiental, social, cultural, econômica, tecnológica e de saúde pública; o desenvolvimento sustentável; a ecoeficiência, mediante a compatibilização entre o fornecimento, a preços competitivos, de bens e serviços qualificados que satisfaçam as necessidades humanas e tragam qualidade de vida e a redução do impacto ambiental e do consumo de recursos naturais a um nível, no mínimo, equivalente à capacidade de sustentação estimada do planeta; a cooperação entre as diferentes esferas do poder público, o setor empresarial e demais segmentos da sociedade; a responsabilidade compartilhada pelo ciclo de vida dos produtos; o reconhecimento do resíduo sólido reutilizável e reciclável como um bem econômico e de valor social, gerador de trabalho e renda e promotor de cidadania; o respeito às diversidades locais e regionais; o direito da sociedade à informação e ao controle social, e; a razoabilidade e a proporcionalidade), vêm sendo sistematicamente utilizado na formulação de políticas públicas como, por exemplo, no caso dos resíduos sólidos $^{8}$.

\footnotetext{
${ }^{5}$ É importante ressaltar que "atividade agrícola" deve ser entendida como "a produção, o processamento e a comercialização dos produtos, subprodutos e derivados, serviços e insumos agrícolas, pecuários, pesqueiros e florestais" Fonte: BRASIL. Lei n. 8.171, de 17 de janeiro de 1991. Dispõe sobre a política agrícola. Disponível em:< http://www.planalto.gov.br/ccivil_03/leis//8171.htm> Acesso: 29.09.2103.

${ }_{7}^{6}$ Aqui também dentro de uma ótica do Direito Econômico.

${ }^{7}$ Inclusive intrinsecamente associado à remuneração de serviços ambientais.

${ }^{8}$ Incisos I a XI, do art. 6을 da Lei n. 12.305, de 02 de agosto de 2010. Fonte: BRASIL. Lei n. 12.305, de 02 de agosto de 2010. Institui a Política Nacional de Resíduos Sólidos; altera a Lei nํㅜ 9.605, de 12 de fevereiro
} 
O objetivo deste trabalho é apontar, descrever, sistematizar e selecionar alguns dos principais parâmetros que devem ser considerados, dentro de uma leitura predominantemente econômica, para efeitos de se propor, avaliar e monitorar as políticas públicas voltadas para a questão ambiental.

Como hipótese principal defende-se que é possível identificar, selecionar, sistematizar e propor critérios que possam orientar o processo de avaliação e acompanhamento das políticas públicas ambientais por parte dos mais distintos segmentos da sociedade e segundo os mais diversos interesses específicos.

\section{METODOLOGIA}

Pretende-se utilizar o método Indutivo, uma vez que se pretende construir generalizações derivadas dos principais preceitos teóricos (aspectos técnicos, jurídicos e econômicos) relacionados à formulação de políticas públicas, consoante constatações particulares extraídas de documentos selecionados e analisados neste trabalho (DA SILVA et MENEZES, 2005).

A natureza desta pesquisa é aplicada, visto que objetiva-se gerar conhecimentos para aplicação prática no sentido da solução do problema aqui abordado. A abordagem da pesquisa será qualitativa, uma vez que as informações produzidas serão analisadas indutivamente. Ainda, a pesquisa será do tipo "exploratória”, "descritiva" e "explicativa", uma vez considerando que se fará uso da pesquisa bibliográfica e documental e análise de experiências relativas ao problema aqui pesquisado, bem como, descrevendo, estabelecendo e identificando relações e principais variáveis dentre as principais características dos materiais a serem aqui investigados (DA SILVA et MENEZES, 2005).

\section{RESULTADOS E DISCUSSÃO}

Durante muito tempo as políticas ambientais focaram primordialmente, no uso de instrumentos de comando e controle. Todavia, é possível constatar que, atualmente, os

de 1998; e dá outras providências. Disponível em: <http://www.planalto.gov.br/ccivil_03/_ato20072010/2010/lei/l12305.htm >. Acesso: 29.09.2010. 
instrumentos econômicos estão sendo utilizados de uma maneira bastante expressiva em termos da propositura de políticas públicas voltadas para os mais diversos escopos ambientais (recursos florestais, recursos hídricos, resíduos sólidos, poluição atmosférica, etc.).

A utilização mais expressiva dos instrumentos econômicos de política ambiental pode ser compreendida, considerando o escopo da sustentabilidade ambiental, mas particularmente, social e econômica, visto tratarem-se dos principais meios de correção das deficiências (falhas) dos mercados ${ }^{9}$ diretamente associados aos atributos ambientais objeto de determinada política ambiental. Isto porque, , quando um mercado for incapaz de regular, via preço, o consumo dos bens naturais (florestais e/ou ambientais), a intervenção pública se faz necessária. Esta, do ponto de vista econômico, é uma questão de pública ambiental (ALMEIDA, 1998; BAUMOL et al. 1979; MARQUES et al. 1999; MUELLER, 1994, PERMAN et al. 1999; POLEMIS, 2000; DA MOTTA, 1999 e SILVA et DA CUNHA 2007).

Segundo Silva et Da Cunha (2007), as principais deficiências de um dado mercado podem ser reputadas aos seguintes fatores: mercados não concorrenciáveis; falta de informação; existência de bens coletivos; e externalidades, dentre outros.

Ainda, como um exemplo ambiental clássico de uma falha de mercado pode-se mencionar que os custos dos bens e serviços muitas vezes não refletem o ônus social total (recursos naturais), dado as chamadas externalidades negativas (poluição ambiental).

A poluição ambiental é vista como uma externalidade negativa porque, ao não ser incorporada, devidamente, via preços, ao Mercado, faz com que a Economia se afaste do ponto "Ótimo de Pareto" (o poluidor maximiza seus lucros, mas o nível máximo de satisfação geral dos agentes não é atingido).

Assim, os economistas neoclássicos ${ }^{10}$ sugerem, alternativamente à intervenção governamental via instrumentos de comando e controle, a adoção de mecanismos de mercado (instrumentos econômicos), de modo a simular um "preço" da degradação

\footnotetext{
${ }^{9}$ Deficiências (falhas) do mercado: aspectos que dificultam o atendimento dos objetivos pré-determinados (sociais, públicos) anteriormente mencionados.

${ }_{10}$ Corrente da Economista que busca incorporar, modernamente, o meio ambiente no processo produtivo de formas tais como fornecedora de insumos e matérias-primas e, portanto, sujeito ao fenômeno de "precificação" (formação de preços via custos de produção, por exemplo).
} 
ambiental que os poluidores devem incorporar aos seus custos privados, ou seja, acabam por "internalizar" as externalidades negativas (poluição ambiental).

\subsection{ESCOLHA DOS INSTRUMENTOS DE POLÍTICA}

No que tange à adequada escolha dos instrumentos de política, quer seja de cunho econômico, público, agrícola, florestal e, em especial, ambiental, Romilson (1999) afiança, que os agentes públicos não se preocupam satisfatoriamente com os efeitos, da produção e do consumo, sobre o meio ambiente. Ainda, os governos se preocupam em incentivar formas de produção e de consumo que sejam as mais eficientes possíveis. E, por fim, que os mercados onde não há intervenção governamental geralmente são ineficientes.

Conforme visto acima, os principais instrumentos de política pública utilizados usualmente pelas autoridades públicas são os instrumentos de comando e controle e os instrumentos econômicos.

Neste sentido, observe-se que as principais críticas à utilização, numa dada política ambiental, por exemplo, dos instrumentos de Comando e Controle (Estudos de Impacto Ambiental - EIA, Licenciamentos, Zoneamentos, Controles Diretos, dentre outros), seriam: as agências governamentais que não conseguem aplicar as leis, por falta de recursos; a falta de opção entre outros instrumentos mais barato não permite que as rendas geradas financiem o controle ambiental; a falta de fiscalização sobre agencias governamentais não possibilita a aplicação da leis; dificuldade do monitoramento e cumprimento das leis, dadas as diversas exigências legais; e os diversos setores governamentais não trabalham em sintonia na aplicação da lei na solução comum dos problemas ambientais (BELLIA, 1996; BARBIERI, 1997; JACOBS, 1991; PERMAN et al. 1999; ROMILSON, 1999; DA MOTTA et al. 1999; SILVA et DA CUNHA 2007).

Por outro lado, as principais observações sobre a utilização, numa dada política ambiental, dos instrumentos econômicos (Impostos, Subsídios, Licenças comercializáveis e Depósitos reembolsáveis) seriam: o interesse por instrumentos econômicos tem crescido recentemente à medida que a adoção de comando e controle não tem conseguido diminuir os impactos sobre o meio ambiente; teoricamente, instrumentos econômicos oferecem o potencial para a crescente flexibilidade regulamentar; e custos mais baixos para reduzir a poluição e atendimento imediato das metas ambientais. 
Grosso modo, a escolha pelo melhor conjunto de instrumentos de política pública, dados os aspectos econômicos mencionados, rege-se pelo binômio "baixo custo administrativo e de implantação" (SILVA et DA CUNHA, 2007; ROMILSON, 1999).

Todavia, a decisão sobre a melhor política a ser adotada pelo ente público deve considerar um conjunto de critérios de avaliação. Segundo, os critérios de avaliação tradicionalmente utilizados na escolha da melhor política pública seriam: eficiência; eficácia; equidade; permanência; custo administrativo; incentivo ao esforço máximo; aceitação política e interferência mínima nas decisões privadas.

Silva et Da Cunha (2007), defendem, ainda que, via de regra, a maior questão que se apresenta para a consecução de objetivos e metas de uma determinada política pública é, como projetar um sistema administrativo apropriado. Dentro deste escopo, apesar da eficiência econômica ser um critério muito importante para avaliar instrumentos de regulação, na prática outros critérios também devem ser considerados. Assim, entendem os autores que eficiência econômica significa que determinado instrumento de política ambiental precisa proporcionar o máximo benefício (econômico, público, florestal e/ou ambiental) ao menor custo.

Em termos de eficácia, um dado instrumento deve proporcionar que os objetivos e metas de uma política ambiental sejam atingidos com o maior grau de certeza.

A equidade de um instrumento de política ambiental buscaria, por seu turno, a divisão dos custos e benefícios de maneira justa, enquanto que a permanência significaria que um determinado instrumento de política ambiental garantiria que os resultados continuariam após a desativação do referido instrumento.

Do ponto de vista de seus custos administrativos, Silva et Da Cunha (2007) defendem que determinado instrumento de política ambiental deveria não somente prever os recursos físicos e financeiros como, também, a geração dos maiores benefícios aos menores custos possíveis. Com isto, políticas ambientais menos onerosas poderiam disponibilizar os escassos recursos públicos para outras finalidades.

Um determinado instrumento de política ambiental deve possibilitar, ainda, que os agentes públicos busquem novos métodos e tecnologias para minimizar seus custos (SILVA et DA CUNHA 2007).

Muito interessante é o critério de avaliação de um instrumento de política ambiental compreendido como "aceitação política", pois, segundo os autores, "para que um 
instrumento de política pública atenda ao critério de aceitação política ele deve ser implantado dentro dos critérios de eficácia, eficiência, equidade e baixo custo administrativo". Deve, ademais, atender os diversos setores sociais (incluindo trabalhadores, empresários e políticos), bem como prever incentivos a sua implantação. Por fim, deve prever elementos de "persuasão" e educação "forçada".

Silva et Da Cunha (2007) afirma, que um determinado instrumento de política ambiental, do ponto de vista da avaliação, deve proporcionar uma interferência mínima ${ }^{11}$ nas decisões privadas.

Entende-se por fim que, com base no conjunto destes pressupostos teóricos, técnicos, econômicos e jurídicos, seria possível os mais distintos segmentos da sociedade se organizarem para fins do processo de avaliação e acompanhamento das políticas públicas ambientais de forma geral.

Assim, exemplificativamente, instrumentos de política ambiental tais como previstos na Política Nacional do Meio Ambiente ${ }^{12}$, poderiam ser avaliados e acompanhados por parte dos mais distintos segmentos da sociedade e segundo os mais diversos interesses específicos (BRASIL, 2013, a) ${ }^{13}$.

\section{CONCLUSÃO}

\footnotetext{
11 Interferência mínima, dentro do particular entendimento dos autores deste trabalho, deveria ser interpretado como "mais consensual", "justo", "menos traumático", enfim, mais "sustentável".

${ }^{12} \mathrm{O}$ estabelecimento de padrões de qualidade ambiental; o zoneamento ambiental; a avaliação de impactos ambientais; o licenciamento e a revisão de atividades efetiva ou potencialmente poluidoras; os incentivos à produção e instalação de equipamentos e a criação ou absorção de tecnologia, voltados para a melhoria da qualidade ambiental; a criação de espaços territoriais especialmente protegidos pelo Poder Público federal, estadual e municipal, tais como áreas de proteção ambiental, de relevante interesse ecológico e reservas extrativistas; o sistema nacional de informações sobre o meio ambiente; o Cadastro Técnico Federal de Atividades e Instrumentos de Defesa Ambiental; as penalidades disciplinares ou compensatórias ao não cumprimento das medidas necessárias à preservação ou correção da degradação ambiental; a instituição do Relatório de Qualidade do Meio Ambiente, a ser divulgado anualmente pelo Instituto Brasileiro do Meio Ambiente e Recursos Naturais Renováveis - IBAMA; a garantia da prestação de informações relativas ao Meio Ambiente, obrigando-se o Poder Público a produzí-las, quando inexistentes; o Cadastro Técnico Federal de atividades potencialmente poluidoras e/ou utilizadoras dos recursos ambientais, e os instrumentos econômicos, como concessão florestal, servidão ambiental, seguro ambiental e outros

${ }_{13}$ Incisos I a XIII, do art. 9o, da Lei n. 6.938/81. Fonte: BRASIL. Lei n. 6.938, de 31 de agosto de 1981. Dispõe sobre a Política Nacional do Meio Ambiente, seus fins e mecanismos de formulação e aplicação, e dá outras providências. Disponível em: < http://www.planalto.gov.br/ccivil_03/leis/l6938.htm> Acesso: 29.09.2013.
} 
É possível identificar parâmetros que possam ser considerados, dentro de uma leitura do binômio "baixo custo administrativo e de implantação", que possam auxiliar na avaliação de políticas públicas voltadas para a questão ambiental.

A partir disto, a decisão sobre a melhor política a ser adotada pelo ente público deve considerar um conjunto de critérios de avaliação, quais sejam: eficiência; eficácia; equidade; permanência; custo administrativo; incentivo ao esforço máximo; aceitação política e interferência mínima nas decisões privadas.

Entende-se que, com base neste conjunto de critérios seria possível, por parte dos mais distintos e interessados segmentos da sociedade, tendo como base os principais pressupostos teóricos, técnicos, econômicos e jurídicos associados a determinado tema, avaliar e monitorar as políticas públicas ambientais de uma forma geral.

\section{REFERÊNCIAS}

ALMEIDA, L. T. de. Política ambiental. Uma análise econômica. Ed. Papirus. Ed. Fundunesp. São Paulo. 1998. 192 págs.

BELLIA, V. "Políticas de Controle Ambiental". Capítulo 6 de Introdução à Economia do Meio Ambiente. Brasília: IBAMA, 1996.

BARBIERI, J. C. Desenvolvimento e Meio Ambiente: as estratégias de mudança da agenda 21. Petrópolis: RJ. Vozes 1997.

BAUMOL, W. J. e Wallace E. OATES. Economics, Environmental Policy, and the Qualility of Life. New Jersey: Prentice-Hall, 1979.

BRASIL. Lei n. 6.938, de 31 de agosto de 1981. Dispõe sobre a Política Nacional do Meio Ambiente, seus fins e mecanismos de formulação e aplicação, e dá outras providências. Disponível em: < http://www.planalto.gov.br/ccivil_03/leis//6938.htm> Acesso: 29.09.2013

Lei n. 8.171, de 17 de janeiro de 1991. Dispõe sobre a política agrícola. Disponível em:< http://www.planalto.gov.br/ccivil_03/leis//8171.htm> Acesso: 29.09.2103.

Lei n. 12.305, de 02 de agosto de 2010. Institui a Política Nacional de Resíduos Sólidos; altera a Lei no 9.605, de 12 de fevereiro de 1998; e dá outras providências. Disponível em: <http://www.planalto.gov.br/ccivil_03/_ato2007-2010/2010/lei/l12305.htm>. Acesso: 29.09.2010.

DA MOTTA, R. S. e MENDES, F. E. "Instrumentos Econômicos na Gestão Ambiental: Aspectos Teóricos e de Implementação". Em ROMEIRO, A. R., B. P. REYDON e M. L. 
LEONARDI. Economia do Meio Ambiente. Teoria, Políticas e Gestão de Espaços Regionais. Campin: SP: UNICAMP, 1999.

DA SILVA, E. L. et MENEZES, E. M. Metodologia da pesquisa e elaboração de dissertação/Edna Lúcia da Silva, Estera Muszkat Menezes. - 4. ed. rev. atual. Florianópolis: UFSC, 2005. 138p.

JACOBS. M. The Green Economy. Environment, Sustainable Development and the Politics of the future. London and Massachusetts: Pluto Press, 1991.

MARQUES, J. F. e COMUNE, A. E. "A Teoria Neoclássica e a Valoração Ambiental". Em ROMEIRO, A. R., B. P. REYDON e M. L. LEONARDI. Economia do Meio Ambiente. Teoria, Políticas e Gestão de Espaços Regionais. Campinas: UNICAMP, 1999.

MUELLER, C. C. "Manual de Economia do Meio Ambiente". Parte III, "A Economia Ambiental Neoclássica". (Nepama, UNB, Versão Preliminar, abril 2000). NAPA. The Environmental Goes to Market. Washington: National Academy of Public Administration, 1994.

PERMAN, R.; MA, Y; McGILVRAY, J. e COMMON, M. Market Failure and Public Policy. Capítulo 6 de Natural Resouce and Environmental Economics. Essex, Inglaterra: Longman, $2^{\mathrm{a}}$ ed., 1999.

POLEMIS, M. Economics Instruments as a means of Enviromental Policy: the case of Taxes. Greece: Universidade de Athens, 2000.

ROMILSON R. P. A Análise Custo-Efetividade na gestão Econômica do Meio Ambiente. Dissertação apresentada no Mestrado em Gestão Econômica do Meio Ambiente Brasília: UNB. 1999.

SILVA, F. L. et DA CUNHA, J. Os instrumentos de política ambiental: critérios de avaliação. Disponível em http://www.cori.rei.unicamp.br/BrasilJapao3/resul_trbs.php?cod=269. Acesso: em 2o sem de 2007. 